\title{
The Missing Link between Obesity and Hepatocellular Carcinoma: IL-6-Mediated STAT-3 Activation as a Key Player in Hepatocarcinogenesis
}

\author{
Yavuz Beyazit Abdurrahim Sayilir Burak Suvak Serkan Torun \\ Department of Gastroenterology, Turkiye Yuksek Ihtisas Training and Research Hospital, Ankara, Turkey
}

Dear Sir,

We read with interest the comprehensive review by Wree et al. [1] on the relationship between obesity and liver tissue. The authors successfully reviewed the current knowledge on the link between adipocytes and hepatocytes with a special emphasis on the contribution of inflammation and cytokines to the pathogenesis. Although possible mechanisms behind this association, especially the link between obesity and hepatocellular carcinoma (HCC), were brilliantly discussed in the light of pertinent literature, we would like to mention a novel mechanism relating obesity with HCC, which we think is important for gaining insight into the cellular mechanisms involved in the pathogenesis.

In their review, the authors mentioned a wide range of possible factors that facilitate progression from obesity to HCC. They also proposed that the main factor that promotes cancer development is leptin. Leptin was shown to promote angiogenesis and facilitate progression of nonalcoholic steatohepatitis to HCC. It is capable of activating multiple signal transduction pathways, such as JNK, protein kinase B, the AKT pathway, and the extracellular signal-regulated kinase pathway in HCC [1]. Although not mentioned by the authors, IL-6-activated signal trans- ducer and activator of transcription 3 (STAT3) in the development of obesitylinked HCC is a novel mechanism of great importance which could open up new diagnostic and therapeutic avenues.

STAT3, which is a well-known transcription factor that also plays a master regulatory role in body weight regulation and glucose homeostasis, has been linked to the proliferation, invasion, angiogenesis, progression and survival of human cancers through the upregulation of target proto-oncogenes of several human cancers, including HCC [2-4]. It was initially described as a DNA-binding activity from IL-6-stimulated hepatocytes, capable of selectively interacting with an enhancer element in the promoter of acute-phase genes, which is also known as the acutephase response element [5]. Although a possible association between liver fat accumulation and HCC development has long been known [6, 7], Park et al. [8] were the first to demonstrate that either dietary or genetic obesity is a direct promoter of HCC development in mice. They also demonstrated that one of the mechanisms that account for the tumor-promoting effect of obesity is the low-grade inflammatory response it induces, which results in an elevated production of cytokines, such as TNF and IL-6, which cause hepatic inflammation and activation of the oncogenic transcription factor STAT3. Activated STAT3 promotes cell survival and proliferation as well as immune responses associated with inflammatory diseases and tumor progression. STAT3 suppression with several agents in HCC cells has also been shown to lead to the induction of apoptosis, reduction in colony-forming ability and enhanced chemosensitivity in HCC cells, supporting the potential action of STAT3 in hepatocarcinogenesis $[9,10]$.

Based on the above-mentioned information, it is reasonable to conclude that a possible association exists between obesity and HCC via activation of STAT3. Although IL-6- and TNF-mediated STAT3 activation, an attractive potential target for the chemoprevention and treatment of liver cancer, plays a major role in the development of HCC, the connection with obesity still warrants further clarification.

\section{Disclosure Statement}

The authors declare no potential conflicts of interest. The authors did not receive any financial support in connection with this article.

\section{KARGER}

Fax +4161306 1234 E-Mail karger@karger.ch www.karger.com
Yavuz Beyazit, MD

Department of Gastroenterology

Turkiye Yuksek Ihtisas Training and Research Hospital

TR-06100 Ankara (Turkey)

Tel. +90 312306 1320, E-Mail yavuzbeyaz@yahoo.com 


\section{References}

1 Wree A, Kahraman A, Gerken G, Canbay A: Obesity affects the liver - the link between adipocytes and hepatocytes. Digestion 2011; 83:124-133.

-2 Beyazit Y, Kekilli M, Kurt M, Sayilir A, Tas A, Onal IK: Role of IL- 6 activated STAT3 and TNF expression in obesity-associated hepatocellular carcinoma. Aliment Pharmacol Ther 2010;32:304-305.

3 Berasain C, Castillo J, Perugorria MJ: Inflammation and liver cancer: new molecular links. Ann N Y Acad Sci 2009;1155:206-221.
4 Tang Y, Kitisin K, Jogunoori W, Li C, Deng CX, Mueller SC, Ressom HW, Rashid A, He AR, Mendelson JS, Jessup JM, Shetty K, Zasloff M, Mishra B, Reddy EP, Johnson L, Mishra L: Progenitor/stem cells give rise to liver cancer due to aberrant TGF-beta and IL-6 signaling. Proc Natl Acad Sci USA 2008, 105:2445-2450.

5 Zhong Z, Wen Z, Darnell JE Jr: Stat3: a STAT family member activated by tyrosine phosphorylation in response to epidermal growth factor and interleukin-6. Science 1994;264 95-98.

-6 Caldwell SH, Crespo DM, Kang HS, AlOsaimi AM: Obesity and hepatocellular carcinoma. Gastroenterology 2004; 127:S97S103.

7 El-Serag HB, Rudolph KL: Hepatocellular carcinoma: epidemiology and molecular carcinogenesis. Gastroenterology 2007;132: 2557-2576.
-8 Park EJ, Lee JH, Yu GY, He G, Ali SR, Holzer RG, Osterreicher $\mathrm{CH}$, Takahashi H, Karin $\mathrm{M}$ : Dietary and genetic obesity promote liver inflammation and tumorigenesis by enhancing IL- 6 and TNF expression. Cell 2010; 140:197-208.

9 Lau CK, Yang ZF, Lam SP, Lam CT, Ngai P, Tam KH, Poon RT, Fan ST: Inhibition of Stat3 activity by YC-1 enhances chemo-sensitivity in hepatocellular carcinoma. Cancer Biol Ther 2007;6:1900-1907.

10 Liu Y, Liu A, Xu Z, Yu W, Wang H, Li C, Lin J: XZH-5 inhibits STAT3 phosphorylation and causes apoptosis in human hepatocellular carcinoma cells. Apoptosis DOI: 10.1007/ s10495-011-0578-0. 